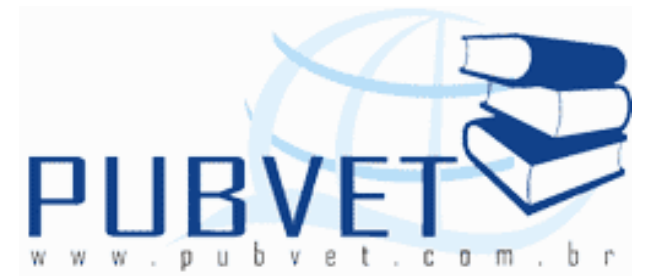

PUBVET, Publicações em Medicina Veterinária e Zootecnia.

\title{
Apicultura no Estado de Alagoas: um estudo sobre práticas desenvolvidas por apicultores em Município do Agreste Alagoano ${ }^{1}$
}

Diogo de Barros Mota Mélo², José Jonas de Melo Alves ${ }^{3}$, Jakes Halan de Queiros Costa ${ }^{4}$, Roger Nicolas Beelen ${ }^{4}$

${ }^{1}$ Parte da Monografia do primeiro autor

2 Zootecnista e servidor do Instituto Federal de Educação, Ciência e Tecnologia de Alagoas

3 Professor de ensino Básico, Técnico e Tecnológico do Instituto Federal de Educação, Ciência e Tecnologia de Alagoas

${ }^{4}$ Professores da Universidade Federal de Alagoas

\section{Resumo}

Este trabalho foi realizado no município de Igací-Al, com o objetivo de relatar as práticas desenvolvidas, os cuidados que os apicultores têm com a atividade, tentando identificar os pontos limitantes da atividade, além de conhecer um pouco os problemas enfrentados pelos mesmos na região. Para a realização deste trabalho, foram entrevistados 10 dos 23 apicultores do município de Igaci/AL. Para a obtenção dos dados de campo foi elaborado questionário contendo questões abertas e fechadas, sobre a situação sócio-econômica das famílias, questões inerentes à situação dos apicultores na Associação, além de questões relacionadas a conhecimento técnico e educacional. Os resultados foram tabulados e sistematizados em planilhas do Excel e expressos em forma 
MÉLO, D.B.M. et al. Apicultura no Estado de Alagoas: um estudo sobre práticas desenvolvidas por apicultores em Município do Agreste Alagoano. PUBVET, Londrina, V. 5, N. 2, Ed. 149, Art. $1001,2011$.

de gráficos e tabelas. Foi constatado que $50 \%$ dos entrevistados realizavam controle de custos e zootécnicos e que $80 \%$ tinham conhecimento sobre a produção das caixas. Outro item foi à prática de substituição de rainhas, onde apenas $20 \%$ aplicam o método da puxada natural, de uma forma irregular. Sobre o produto explorado $60 \%$ mel e $40 \%$ mel e cera. Questionados sobre a capacidade de realizar uma revisão $90 \%$ disseram que faziam, porém $70 \%$ não sabiam quais os parâmetros utilizados para esta prática. Onde processa o mel $90 \%$ deles realiza esta prática em uma casa do mel e $10 \%$ na própria residência. Questionados sobre a procedência do mel $60 \%$ responderam que não conhecia e os outros $40 \%$ não souberam responder qual seria esta procedência. Sobre se realizavam análise, nenhum dos entrevistados pratica, porém, todos teriam vontade de analisar seu mel, mas não souberam responder qual seria a análise. Quanto ao conhecimento dos produtos das abelhas, $80 \%$ disseram que sim, da mesma maneira que quando questionados sobre o maior benefício da abelha para o homem. Com isso o desconhecimento de técnicas adequadas de manejo apícola afeta de forma efetiva na produtividade da apicultura região de Igací.

Palavras-chave: Apicultura, perfil, Igací.

\title{
Beekeeping in Alagoas: a study on practices developed by beekeepers in the Municipality of Wild Alagoas
}

\begin{abstract}
This study was conducted in the municipality of Igaci-AL, with the objective of describing the practices of the care that beekeepers have with activity, trying to identify the limiting activity, and know a little of the problems faced by them in the region. For this work, we interviewed 10 of 23 beekeepers in the municipality of Igací / AL. To obtain the field data was prepared questionnaire with open and closed questions on the socioeconomic status of families, issues related to the situation of beekeepers in the Association, as well as issues related to technical knowledge and education. The results were tabulated and
\end{abstract}


MÉLO, D.B.M. et al. Apicultura no Estado de Alagoas: um estudo sobre práticas desenvolvidas por apicultores em Município do Agreste Alagoano. PUBVET, Londrina, V. 5, N. 2, Ed. 149, Art. $1001,2011$.

systematized in Excel spreadsheets and expressed in the form of graphs and tables. It was found that $50 \%$ used to control costs and husbandry, and $80 \%$ had knowledge about the production of boxes. Another item was the practice of queen replacement, where only $20 \%$ use the method of the natural pull of an irregular shape. About the product exploited honey $60 \%$ and $40 \%$ honey and wax. Asked about the ability to carry out a review $90 \%$ said they did, but $70 \%$ did not know what the parameters used for this practice. Where the honey processing $90 \%$ of them realize this practice in a house of honey and $10 \%$ in the residence. Asked about the origin of honey $60 \%$ said they did not know and the other $40 \%$ could not answer where the exact origin. On examination took place, none of the respondents practice, however, all will have to analyze your honey, but could not answer what would be the analysis. The knowledge of bee products, $80 \%$ said yes, the same way when asked about the greatest benefit to the bee man.

Keywords: Beekeeping, Profile, Igací

\section{Introdução}

Algumas práticas de manejo podem influenciar diretamente a produtividade da apicultura, como por exemplo, a substituição de rainhas e o uso da suplementação alimentar.

Para a difusão de uma técnica de produção, devemos considerar, além dos aspectos climáticos, os aspectos culturais, o nível de desenvolvimento do sistema de produção existente na região e o conhecimento técnico dos produtores. Muito mais do que considerar o clima da região, deve-se ter conhecimento sobre a cultura e tradição dos apicultores.

Diante disto, podemos considerar que, na apicultura, muitas práticas de manejo são realizadas conforme a percepção de cada apicultor em conjunto com os fatores culturais do meio no qual está inserido. Sendo assim, a importância dada a uma determinada prática pode ser variável para distintas 
MÉLO, D.B.M. et al. Apicultura no Estado de Alagoas: um estudo sobre práticas desenvolvidas por apicultores em Município do Agreste Alagoano. PUBVET, Londrina, V. 5, N. 2, Ed. 149, Art. $1001,2011$.

regiões, tanto pelas condições físicas do meio, como pelas condições culturais que atuam nesta localidade.

Neste trabalho pretenderam-se relatar as práticas desenvolvidas, os cuidados que os apicultores têm com a atividade, tentando identificar os pontos limitantes da atividade, além de conhecer um pouco os problemas enfrentados pelos mesmos na região.

\section{Revisão de literatura}

As abelhas africanas foram introduzidas no Brasil em 1956, com o intuito de se executar um programa de melhoramento genético que fosse capaz de aumentar a produção de mel do País, associada a uma baixa agressividade. Entretanto, devido a problemas na manipulação, ocorreu a enxameação de algumas famílias, o que levou ao início de um processo de cruzamentos naturais com abelhas de origem européia que haviam sido trazidas pelos imigrantes entre 1840-1850, propiciando a formação de um híbrido, a abelha africanizada (SOARES, 2004).

Ainda de acordo com SOARES (2004) essa abelha africanizada, embora muito produtiva, causou forte impacto no início de sua dispersão, devido ao elevado grau de agressividade que ela apresentava e às próprias deficiências dos apicultores e da população em geral de que não sabiam como trabalhar e conviver com ela. Houve abandono da atividade apícola, morte de pessoas, animais e a produção de mel, que já era baixa, praticamente zeraram.

Entretanto, com o passar do tempo, os apicultores se conscientizaram que essa abelha poderia ser controlada e explorada com êxito, se houvesse uma adequação e uma total reformulação de técnicas e conceitos válidos para as abelhas européias, mas que eram desastrosos para a abelha africanizada. Baseando-se em suas próprias experiências e nas informações geradas pelos centros de pesquisas, os apicultores brasileiros conseguiram assimilar as novas 
MÉLO, D.B.M. et al. Apicultura no Estado de Alagoas: um estudo sobre práticas desenvolvidas por apicultores em Município do Agreste Alagoano. PUBVET, Londrina, V. 5, N. 2, Ed. 149, Art. $1001,2011$.

técnicas e passaram novamente a acreditar que seria possível uma apicultura eficiente com abelhas africanizadas (NETO, 2006).

Segundo Paxton (1995) a apicultura é uma das poucas atividades agropecuárias que atende aos três requisitos da sustentabilidade: o econômico, o social e o ecológico. Sendo assim, fornece renda para o apicultor, ocupa mão-de-obra familiar ou contratada e contribui para a preservação da flora nativa, pois é dela que são extraídos o néctar e o pólen, componentes essenciais para a vida das colméias.

A região Nordeste apresenta um perfil característico da região melífera, em função de características de vegetação, de clima e de cultura. A biodiversidade é essencial para a produção agrícola, sendo a chave para a produção de sistemas agrícolas balanceados, oferecendo uma série de benefícios à agricultura, garantindo a produtividade e a qualidade ambiental (CASTRO, 1998, citado por SILVA, 2000).

O Estado de Alagoas possui aptidão natural para a exploração apícola, a partir de sua vegetação com grande diversidade de floradas, condições climáticas favoráveis e número crescente de apicultores. Porém a apicultura no estado é uma atividade recente e caracteriza-se pela produção como atividade secundária, através de pequenos apiários fixos, baixo manejo dos enxames, desconhecimento da flora apícola, falta de controle de qualidade do produto, e cooperativismo incipiente. A distância entre o potencial produtivo e a produção do estado é fato perfeitamente visível. (PEREIRA e VILELA, 2003)

De acordo com Vilela (2003) vários produtos se apresentam, para Alagoas, como um potencial significativo de produção e conseqüente benefícios para o estado, como o aumento da produção através da polinização, na agricultura, a geração de renda para produtores e trabalhadores rurais e produtores de insumos, além do favorecimento do meio ambiente através da recuperação de áreas degradadas por erosão, queimadas e desmatamentos. 
MÉLO, D.B.M. et al. Apicultura no Estado de Alagoas: um estudo sobre práticas desenvolvidas por apicultores em Município do Agreste Alagoano. PUBVET, Londrina, V. 5, N. 2, Ed. 149, Art. $1001,2011$.

\section{Material e métodos}

Este trabalho foi realizado no município de Igací/AL, no período entre julho a dezembro de 2007. Foram entrevistados 10 dos 23 apicultores envolvidos diretamente com a Associação dos Apicultores do Município. Devese salientar que os demais não foram encontrados devido a imprevistos de caráter pessoal como viagens e/ou até mesmo a ausência durante a aplicação dos questionários e entrevistas realizadas no período pré-estabelecido na elaboração do projeto.

Os 10 entrevistados correspondem a $66,67 \%$ do universo populacional considerado oficialmente associado da Associação de Apicultores. O tamanho da amostra encontra-se de acordo com os parâmetros definidos por Shimakura (2002) em sua teoria de limite central, considerando-se a homogeneidade da população pesquisada.

As informações coletadas foram feitas à base de observação participativa através do convívio com os apicultores realizando cursos, palestras, visitas técnicas, reuniões, entre outros.

Como roteiro para as entrevistas foi utilizado questionário contendo questões abertas e fechadas e um levantamento de dados sobre os seguintes parâmetros: número de apicultores, ligação destes com Associações ou Cooperativas, motivos para a criação de abelhas, produção de mel, situação econômica do produtor de mel e conhecimento técnico e educacional dos apicultores.

Os resultados foram tabulados em planilha do Excel e representados em gráficos e tabelas. A partir dos dados coletados foi feita sistematização a fim de serem identificadas a evolução do grupo, as limitações e as potencialidades. 
MÉLO, D.B.M. et al. Apicultura no Estado de Alagoas: um estudo sobre práticas desenvolvidas por apicultores em Município do Agreste Alagoano. PUBVET, Londrina, V. 5, N. 2, Ed. 149, Art. $1001,2011$.

\section{Resultados e discussão}

Os resultados apresentados a seguir são referentes ao perfil dos apicultores a partir das práticas desenvolvidas pelos apicultores do município de Igací/AL entrevistados que reforçam os conceitos, estudos e documentários apresentados no embasamento teórico deste trabalho.

\section{Controle Zootécnico e de Custos}

Entre os apicultores que fazem controle zootécnico e realizam controle de custos, há uma situação equilibrada no que diz respeito a este aspecto, onde a metade dos apicultores faz e a outra metade não realiza o controle. Vale ressaltar a importância destas práticas, pois são dados que o produtor obtém para melhoria da criação. Com eles fica fácil saber onde está o erro da produção e quando está ocorrendo lucro ou prejuízo. A leitura da realidade indica a existência de dificuldades de alguns apicultores com a atividade, em parte relativa ao acesso a informação sobre a atividade/exploração. Eles não possuem qualquer tipo de fichas de controle como, por exemplo: ficha de revisão, controle de estoque, controle de dados, nem mesmo anotações. Nem mesmo sabem a situação financeira da atividade, praticando uma apicultura extensiva.

Daqueles que responderam sim, foram questionados quais controles realizavam em suas propriedades, como resultado, nenhum dos entrevistados tem noção do que é, e qual a importância do controle. Isso mostra a falta de conhecimento do que pode ser considerado importante para a criação e, que até mesmo apicultores não sabem o que controlar deixando muito a desejar neste aspecto. A falta de conhecimento e/ou a falta de incentivo para a atividade pode ser considerada como responsável. 
MÉLO, D.B.M. et al. Apicultura no Estado de Alagoas: um estudo sobre práticas desenvolvidas por apicultores em Município do Agreste Alagoano. PUBVET, Londrina, V. 5, N. 2, Ed. 149, Art. $1001,2011$.

\section{Quantidade de Ninhos existentes por apicultor}

A tabela 1 retrata o resultado à pergunta sobre quantas caixas cada um possuía, se todas estavam povoadas, se eles tinham conhecimento da produção dos últimos três anos, além da produção por caixa.

Tabela 03 - Quantidade de caixas de cada entrevistado e número de caixas povoadas

\begin{tabular}{c|ccc}
\hline Entrevistados & Quantidade de caixas & $\begin{array}{c}\text { Caixas } \\
\text { Povoadas }\end{array}$ & $\begin{array}{c}\text { Quant. Caixas / Caixas } \\
\text { povoadas } \\
\mathbf{( \% )}\end{array}$ \\
\hline $\mathbf{1}$ & 15 & 15 & 100,00 \\
$\mathbf{2}$ & 20 & 20 & 100,00 \\
$\mathbf{3}$ & 23 & 15 & 65,22 \\
$\mathbf{4}$ & 20 & 20 & 100,00 \\
$\mathbf{5}$ & 25 & 25 & 100,00 \\
$\mathbf{6}$ & 30 & 22 & 73,33 \\
$\mathbf{7}$ & 23 & 18 & 78,26 \\
$\mathbf{8}$ & 30 & 30 & 100,00 \\
$\mathbf{9}$ & 10 & 7 & 70,00 \\
$\mathbf{1 0}$ & 30 & 30 & 100,00 \\
\hline Total & 226 & 202 & 88,86 \\
\hline
\end{tabular}

Nota-se que em alguns casos o número de povoamento é menor que a quantidade total de caixas, isso pode explicar uma produtividade inferior da esperada, conforme demonstrada na tabela. A falta de atenção, de anotação ou até mesmo a não realização de algumas atividades como divisão e captura de enxames são responsáveis pela pouca informação na produção e na exploração. Essas percentagens podem ser ainda menores, pois os mesmos não têm um controle efetivo da atividade. 
MÉLO, D.B.M. et al. Apicultura no Estado de Alagoas: um estudo sobre práticas desenvolvidas por apicultores em Município do Agreste Alagoano. PUBVET, Londrina, V. 5, N. 2, Ed. 149, Art. $1001,2011$.

\section{Conhecimento do Apicultor sobre sua Produção}

A maioria dos entrevistados ( $80 \%$ ) tinha conhecimento sobre a produção apícola nos últimos três anos. Ao comparar com a tabela anterior nota-se que em alguns casos a produção - apresentada no quadro 1- não condiz com o verdadeiro número de caixas citado anteriormente. Alguns apicultores possuem a mesma quantidade de caixas povoadas que outros e conseguem 0 dobro da produção, outros possuem a mesma produção com uma quantidade inferior de caixas. Foi constatado que alguns apicultores não conhecem ao certo sua produção e, portanto, não há condições de informar, com conviç̧ão, sua produtividade. Isto reforça que alguns produtores não têm noção do que está se passando na atividade por falta de anotações e controle na atividade.

Quadro 01 - Respostas dos apicultores entrevistados sobre se sabiam qual a produção apícola nos últimos três anos e a média de produção de mel/caixa.

\begin{tabular}{c|cc}
\hline Entrevistados & Produção nos últimos 3 anos & $\begin{array}{c}\text { Média produção } \\
\text { (kg/caixa) }\end{array}$ \\
\hline $\mathbf{2}$ & Sim & 25 \\
$\mathbf{3}$ & Sim & 6 \\
$\mathbf{4}$ & Não & - \\
$\mathbf{5}$ & Sim & 6 \\
$\mathbf{6}$ & Sim & 30 \\
$\mathbf{7}$ & Sim & 6 \\
$\mathbf{8}$ & Sim & 6 \\
$\mathbf{9}$ & Sim & 30 \\
\hline $\mathbf{1 0}$ & Não & - \\
\hline
\end{tabular}


MÉLO, D.B.M. et al. Apicultura no Estado de Alagoas: um estudo sobre práticas desenvolvidas por apicultores em Município do Agreste Alagoano. PUBVET, Londrina, V. 5, N. 2, Ed. 149, Art. $1001,2011$.

\section{Aquisição de Enxames}

A seguir é mostrado outro questionamento referente à como o apicultor adquiria seu enxame. Devido ao baixo poder aquisitivo todos os apicultores capturam seus enxames. Destes, $80 \%$ capturam nas matas da região e $20 \%$ utilizam caixa isca, entretanto, de uma forma bastante rudimentar, não tendo cuidado e preocupação com práticas corretas, onde alguns utilizam até fumaça proveniente de origem animal como as fezes, mesmo sabendo da má qualidade do mesmo. Porém uma forma bastante econômica de adquirir é dividir seus enxames, e nenhum deles realiza esta prática por não ter conhecimento dos métodos existentes. Isso pode ser comprovado pelo fato que alguns apicultores não povoam todas as suas caixas ocasionando prejuízo na produção.

\section{Substituição de Rainhas pelos apicultores}

Dos questionados $80 \%$ não realizam a substituição enquanto $20 \%$ realizam a substituição. Porém esta troca ocorre de maneira irregular e sem controle utilizando o método da puxada natural. Questionados de como faz a prática, nenhum deles conseguiu responder qual o procedimento do método.

\section{Produtos explorados pelos apicultores}

Sobre os produtos explorados pelos apicultores se obteve um resultado interessante, onde cerca de $60 \%$ exploram a produção de mel e $40 \%$, mel e cera. A produção de mel é feita de forma irregular no que se diz respeito a técnicas utilizadas. Já na produção de mel e cera os apicultores também não sabem explicar de forma clara como exploram a cera.

\section{Revisão de Enxames}

Outro item de bastante importância para a produção é a capacidade que o apicultor tem de realizar uma revisão. Prática capaz de influenciar positivamente na atividade, pois nela o produtor será capaz de ter a certeza de como está à situação do enxame, o que fazer para melhorá-lo, quando colocar 
MÉLO, D.B.M. et al. Apicultura no Estado de Alagoas: um estudo sobre práticas desenvolvidas por apicultores em Município do Agreste Alagoano. PUBVET, Londrina, V. 5, N. 2, Ed. 149, Art. $1001,2011$.

uma melgueira, quando colher o mel, entre outros pontos. Conforme o resultado, 90\% disseram que sabem realizar uma revisão, porém questionados sobre quais os parâmetros utilizados $70 \%$ não souberam responder o que observam. E os outros 30\%, responderam que observam cria, larva, se o enxame está forte e se tem alimento. Esquecendo de pontos importantes como a presença de pragas e doenças, a presença e condição da rainha etc. Dos entrevistados $30 \%$ afirmaram que utilizam ficha de controle de revisão, mas não souberam informar como seria esta ficha.

\section{Processamento e procedência de Mel}

A respeito do processamento de mel, $90 \%$ dos apicultores responderam que processam em uma casa do mel e $10 \%$ processam na própria casa. Porém os produtores não seguem procedimentos corretos para o processamento do mel. A casa do mel não tem qualquer selo de inspeção.

Quando perguntados sobre a procedência do mel $60 \%$ dos entrevistados responderam que conheciam, porém não relataram qual seria. Aprofundando nesta questão foram questionados se faziam análise do seu mel e todos responderam que não realizavam nenhum tipo. É importante registrar que todos gostariam de analisar seu mel, porém não sabiam qual tipo de análise fazer.

\section{Conclusões}

O desconhecimento de técnicas adequadas de manejo apícola afeta de forma efetiva na produtividade da apicultura região de Igací.

Possíveis problemas com a comercialização do mel ocorrem devido ao não conhecimento da qualidade do mesmo.

O despreparo técnico e educacional prejudica a divulgação e aumento de criadores na região, pois gera uma incerteza na atividade.

A falta de capacitação periódica limita a expansão da atividade. Entretanto para o fortalecimento do grupo na região algumas práticas 
MÉLO, D.B.M. et al. Apicultura no Estado de Alagoas: um estudo sobre práticas desenvolvidas por apicultores em Município do Agreste Alagoano. PUBVET, Londrina, V. 5, N. 2, Ed. 149, Art. $1001,2011$.

poderiam ser feitas para tentar minimizar os problemas do grupo: como a existência de unidade de beneficiamento e capacitações periódicas no que diz respeito a manejo, doenças, alimentação, beneficiamento, controle entre outros, a fim de serem solucionados os problemas existentes.

\section{Referências bibliográficas}

NETO, Francisco Leandro de Paula. P324a Apicultura nordestina: principais mercados, riscos e oportunidades. Fortaleza: Banco do Nordeste do Brasil, 2006. 78 p. (Série Documentos do ETENE, n. 12).

PAXTON, R. Conserving wild bees. Bee World. No.76, Vol.2, p.53-55. Inglaterra, 1995.

PEREIRA, F. de M.; VILELA, S. L. de O. Estudo da cadeia produtiva do mel no estado de Alagoas. Teresina: SEBRAE, 2003. $65 \mathrm{p}$.

SEAGRI.

Disponível

em:

http://www.seagri.ba.gov.br/programas.asp?prt=true\&qact=viewprogram\&prgid=7 Acesso em: 18 Jan. 2008.

SHIMAKURA, S. E., Teorema Central do Limite. Disponível em: http://leg.ufpr.br/ shimakur/CE003/node36.html. Acesso em: 18 de Jun. 2007.

SILVA, R. A.. Fenologia e forrageamento pelos apoidea em plantas do Módulo de Apicultura do CCA/CAMPUS III - Areia (Microrregião do brejo paraibano). 2000, 50p. Monografia (Graduação em Zootecnia) - Universidade Federal da Paraíba/Areia.

SOARES, A. E. E. Captura de enxames com caixas iscas e sua importância no melhoramento de abelhas africanizadas. In: CONGRESSO BRASILEIRO DE APICULTURA, 16. 2004, Natal. Anais... Natal: CBA, 2004. 1 CDROM.

VILELA, S. L. de O. (Org.). Cadeia produtiva do mel no estado do Piauí. Teresina: Embrapa Meio-Norte, 2003. 121 p. 